\title{
SANGRE DE AMOR CORRESPONDIDO, UNA NOVELA TRADUCIDA. TRADUCCIÓN Y EXPERIENCIA DE LO EXTRANJERO EN EL EXILIO BRASILEÑO DE MANUEL PUIG
}

\author{
María Guillermina Torres \\ Instituto de Investigaciones en Humanidades y Ciencias Sociales \\ Universidad Nacional de La Plata/CONICET \\ La Plata, Argentina \\ torresrecaguillermina@gmail.com
}

RESUMEN / ABSTRACT

En 1980, Manuel Puig se trasladó a Río de Janeiro donde comenzó a preparar su séptima novela, la que escribiría a partir de las conversaciones en portugués que mantuvo y grabó con un albañil que trabajaba para él. En 1982 fueron publicadas las versiones en portugués y en español de la novela Sangre de amor correspondido, ambas escritas por el autor argentino. A partir de una lectura del archivo del escritor y mediante el cotejo de las versiones, se sostendrá que la novela en español se ofrece al lector como "novela traducida", puesto que lo que se lee se afirma siempre como traducción de algo, nunca como un original. Puig crea una lengua y hace de ella un territorio donde mostrar una experiencia de lo extranjero: el modo en que lo otro puede manifestarse en la propia lengua.

Palabras clave: Manuel Puig, Brasil, Sangre de amor correspondido, traducción, experiencia de lo extranjero.

\section{SANGRE DE AMOR CORRESPONDIDO AS A TRANSLATED NOVEL. TRANSLATION AND EXPERIENCE OF THE FOREIGN IN MANUEL PUIG'S BRAZILIAN EXILE}

In 1980, Manuel Puig moved to Rio de Janeiro where he began to prepare his seventh novel, which he would write based on the conversations in Portuguese that he maintained and recorded with a bricklayer who worked for him. In 1982 the Portuguese and Spanish versions of the novel Sangre de amor correspondido were published, both written by the Argentine author. From a reading of the writer's archive and by comparing the versions in both languages, it will be argued that the novel in Spanish offers itself to the reader as a translated novel, since 
what is read is always affirmed as a translation of something, never as an original. Puig creates a language and makes it a territory where to show an experience of the foreign: the way in which in the own language the other can manifest itself.

KEYWORDS: Manuel Puig, Brazil, Sangre de amor correspondido, translation, experience of the foreign.

Recepción: 02/04/2020

Aprobación: 08/09/2020

\section{EL PORTUGUÉS, OTRA LENGUA EXTRANJERA}

Después de haberse exiliado en México y Estados Unidos, en 1980 el escritor argentino Manuel Puig (1932-1990) se trasladó a Río de Janeiro donde permaneció hasta 1989. Una vez instalado, comenzó a preparar su séptima novela, Sangre de amor correspondido (1982), la que escribiría a partir de las conversaciones en portugués que mantuvo y grabó con uno de los albañiles que trabajaba para él en los arreglos de su departamento en el barrio carioca de Leblon y al que le pagaría, a cambio de esas charlas, un dinero extra.

Esta novela en particular, y la producción correspondiente al periodo de su exilio brasileño en general, fue poco atendida por la crítica especializada ${ }^{1}$. En primer lugar, los estudios que se han centrado en el abordaje del corpus escrito durante su exilio suelen priorizar las producciones correspondientes a los periodos transcurridos en México (1974-1976) y Estados Unidos (19761980). En segundo lugar, cuando el análisis crítico focaliza el terreno de las lenguas extranjeras y la traducción en la literatura de Puig, en cruce o no con el exilio, los intereses giran en torno al inglés, lengua en la que escribiría sus primeros guiones cinematográficos y que el autor asociaría a Hollywood y al cine ${ }^{2}$. Así, suele suceder que Sangre de amor queda solapada al abordaje

En varios de los trabajos, ensayos y tesis sobre la obra de Manuel Puig se hace referencia a esta novela. Sin embargo, son escasos los dedicados exclusivamente a la lectura de Sangre de amor correspondido. Puede destacarse un artículo breve de Paula Siganevich: "Brasileridad, traducción y género en la escritura de Manuel Puig". En José Amícola y Graciela Speranza (eds.), Encuentro Internacional Manuel Puig, Rosario, Beatriz Viterbo, 1998, pp. 237-241.

2 Ver: Rozenkratz, Guillermina. El cuerpo indómito. Espacios del exilio en la literatura de Manuel Puig. Buenos Aires: Simurg, 1999; Goldchluk, Graciela. El diálogo interrumpido. 
crítico de la novela Maldición eterna a quien lea estas páginas (1980), escrita unos años antes durante su segunda estadía en Nueva York y que, de modo semejante a la primera novela escrita en Brasil, tuvo una versión primero en la lengua del escritor y luego en la lengua extranjera-Maldición eterna en inglés y Sangre de amor en portugués ${ }^{3}$-, ambas realizadas por Puig. Puesto que para una y otra recurrió a sujetos reales y a sueldo con quienes mantuvo conversaciones a partir de las cuales escribiría luego, Sangre de amor y Maldición eterna se han considerado como un "par solidario" (Kozak 132133). Ahora bien, desde esa perspectiva, que enfatiza una suerte de igualdad procedimental, se ignora la diferencia irreductible de cada encuentro con esas lenguas, así como también todo lo que hay de diferente entre el portugués y el inglés en la biografía, el imaginario y la carrera de Puig y, a su vez, de estas lenguas respecto de la lengua materna del escritor.

Estos caminos suponen una visión de la traducción como una operación siempre igual a sí misma, como un algoritmo que desconoce las singularidades de cada lengua y el particular vínculo del escritor con cada una. Pero, además, en Maldición eterna, a diferencia de lo que sucede en Sangre de amor, la lengua extranjera se hace presente no solo en el proceso de creación sino también a nivel de la representación, puesto que la novela misma narra y reflexiona acerca de la vivencia que tiene lugar cuando se escribe en el exilio en Nueva York, cuando se es extranjero en una ciudad y en una lengua. Es precisamente en esta cuestión en lo que repara la crítica cuando analiza aspectos de la traducción en la novela, pues lo que interesa en ella es su discurso sobre la traducción, lo que se representa o dice al respecto. Para Logie y Romero, Maldición eterna pone en abismo el código de su funcionamiento, ya que "cuenta el relato de su propia historia y vuelve explícitas las reglas que subyacen a su creación" (15); Cabrera entiende la novela como una parodia de la traducción que "desarmó la representación tradicional de la traducción" (216); para Kozak, por su parte, la novela cuenta "el lento y arduo proceso

Marcas de exilio en los manuscritos mexicanos de Manuel Puig, 1974-1978. Santa Fe: UNL, 2011; y Cabrera, Delfina. Las lenguas vivas. Zonas de exilio y traducción en Manuel Puig. Buenos Aires: Prometeo Libros, 2016.

Maldición eterna a quien lea estas páginas tuvo su primera edición en 1980, por la editorial Seix Barral y fue luego publicada en 1982, en inglés, como Eternal Curse on the Reader of these Pages, por la editorial de la Universidad de Minnesota. Sangue de amor correspondido fue publicada por la editorial carioca Nova Fronteira en 1982, con la revisión de Luiz Otávio Barreto Leite. 
de 'confrontación' por el cual se puede dar la reconstitución del nombre propio mutilado en relación directa con el exilio: ser extranjero es no poder sentir el lenguaje" $(145)^{4}$.

Si se siguen los testimonios de Puig, el mismo autor sostuvo que lo que le interesó del entrevistado neoyorkino era lo que "decía" - la visión de un exiliado afásico sobre la ciudad-. Diferentemente, cuando justificó la elección del entrevistado brasileño para la novela Sangre de amor, afirmó que lo que quiso registrar fue "un habla": "Sí, eso me llamó la atención y quise registrar su habla, tratar de captar su lenguaje, sin pensar que además había en ese hombre una historia. Y menos aún que esa historia podía transformarse en una novela" (Puig cit. en Romero 240).

En consonancia con lo expresado en la entrevista, puede decirse que el lugar de la lengua extranjera y de la traducción en Sangre de amor es factible de ser leído, no ya a partir de su representación - de lo que se dice de la experiencia y de lo que se muestra de esa experiencia-, sino en las inflexiones por las cuales ese "habla" se hace presente, en los modos en que la escritura es capaz de albergar esa otra lengua. Tomando esto como punto de partida, a continuación, se buscará pensar la novela Sangre de amor en la consideración del trabajo que Puig realizó con el habla del otro en el proceso de escritura $y$, en particular, la manera en que puede leerse la presencia insuprimible de esa lengua extranjera en la novela en español.

Para llevar adelante esta lectura se recurrirá, por un lado, a las versiones de la novela tanto en español como en portugués -Sangre de amor y Sangue de amor correspondido, respectivamente- $\mathrm{y}$, por otro, al archivo del escritor.

En el sitio ARCAS de la Biblioteca "Profesor Guillermo Obiols", de la Facultad de Humanidades y Cs. de la Educación de la Universidad Nacional de La Plata, se encuentran a disposición de los usuarios una gran cantidad de manuscritos de Manuel Puig, cuya organización estuvo a cargo de la Dra. Graciela Goldchluk. Entre ellos se cuenta con los manuscritos que dieron origen a las novelas escritas por Puig en ambas lenguas, Sangre de amor y

\footnotetext{
A modo de excepción, un artículo breve de Graciela Goldchluk realiza un acercamiento a la novela a partir de la lengua que allí se pone en juego por la traducción: "Escribir la voz del otro: la lengua de la traducción en Maldición eterna a quien lea estas páginas, de Manuel Puig". Actas del I Congreso de la Delegación Argentina de la Asociación de Lingüística y Filología de América Latina (ALFAL) y V Jornadas Internacionales de Filología Hispánica “Identidades dinámicas: variación y cambio en el español de América”, 2012. Disponible en: http://jornadasfilologiaylinguistica.fahce.unlp.edu.ar/
} 
Sangue de amor: desgrabaciones, pre-textos prerredaccionales, pre-textos redaccionales en portugués, pre-textos redaccionales de la primera, segunda y tercera versión en español, pruebas de imprenta y traducciones de otros corregidas por el autor. Para la realización de las hipótesis, el foco estuvo puesto en las desgrabaciones de las conversaciones con el albañil, los pretextos prerredaccionales, los pre-textos redaccionales en portugués y la primera versión de los pre-textos redaccionales en español ${ }^{5}$. En la consideración de estos materiales, se sostendrá la hipótesis de que la novela en español -Sangre de amor- se ofrece al lector de Puig como "traducida", puesto que, a partir de un trabajo con la propia lengua, lo que se lee se afirma siempre como traducción de algo, nunca como un original. Por el enrarecimiento de la lengua materna, el texto reclama que se le reconozca su naturaleza extranjera: se trata de una "novela traducida", en la que la lengua del escritor abre espacio y muestra la presencia del portugués a partir de un conjunto de operaciones que la albergan, señalándola incesantemente; entre ellas, está la no traducción de los nombres propios, el uso de los pronombres de tercera persona y la presencia de sufijos diminutivos. A través de este conjunto de estrategias de traducción extranjerizante, Puig apostará por una novela en español que señale su propia alteridad.

5 De estas fuentes fueron tomadas las imágenes que se reproducen en este escrito. Resulta necesario realizar dos aclaraciones: en primer lugar, en relación con el archivo del escritor en este trabajo, el mismo ha tenido un lugar preponderante por la calidad del material, por el tipo de hipótesis que permitió plantear y por la riqueza que implicó experimentar su lectura. Sin embargo, la puesta en marcha del "Archivo Digital Manuel Puig" y de los aportes de la crítica genética -en particular, sus conceptualizaciones en torno a los manuscritos de escritores y al modo de organizarlos para su análisis-, fueron puestas en juego en función de las hipótesis críticas que se sostienen en este trabajo y en ningún momento se tuvo como horizonte realizar una lectura geneticista de las novelas. En segundo lugar, en lo que se refiere a la cuestión de la traducción, vale aclarar que los análisis realizados implicaron un abordaje desde las teorías de la traducción literaria en función de las hipótesis crítico-literarias. Es decir, no se buscó un análisis exhaustivo ni sistemático del trabajo de traducción de Puig -de hecho, la afirmación "Puig tradujo" resulta problemática si se atiende al modo en que en su literatura funcionan las categorías de "original", "traducción" y "copia", entre otras-sino que la propuesta se orienta a ver de qué manera operó la traducción y sus posibles concepciones para aportar a las reflexiones crítico-literarias acerca de la obra de Manuel Puig y, en particular, a su tramo brasileño. 


\section{PROCESO DE ESCRITURA}

Como en las anteriores novelas de Puig, la estructura de Sangre de amor es, fundamentalmente, la de un diálogo, que en este caso se inicia con una pregunta que dará el pie al desarrollo de la narración. Esa pregunta es formulada por María da Gloria, quien le pide al protagonista y voz principal de la conversación que recuerde cuál fue la última vez que la vio. Josemar da su primera respuesta y a partir de allí comienza un relato impulsado por el intento, primero extraviado y luego desesperado, de contar cómo logró que María da Gloria, su novia de la juventud en el pueblo, le entregara su virginidad. Pero, a medida que la narración avanza, el lector percibe que lo que lee, antes que un diálogo, es en realidad un monólogo en el que Josemar contesta a las voces de su cabeza -su antigua novia, su hermano, su madre-; de modo que la narración prosigue a partir de las múltiples versiones que da de ese encuentro sexual: primero en un hotel, después en un galpón, con un Maverick, a pie, con un Gordini. Así, la anécdota que da lugar al relato se revela no solo como falsa sino como inversa: esa voz acaba contando que no logró que su novia le entregara su virginidad, que fue ella quien lo abandonó y que es él quien acaba enloqueciendo. Como observa Amícola, la fabulación del monólogo de Josemar "es el intento (exhibido como fallido ante el lector) de cubrir su incapacidad y su vergüenza con la narración que se muerde la cola" (306).

Según puede leerse en sus cartas, Puig comenzó a trabajar en su séptima novela muy poco tiempo después de haber llegado a Brasil en $1980^{6}$. El portugués no es una lengua que hubiera estudiado, como estudió inglés, francés o italiano, las lenguas prestigiosas del cine ${ }^{7}$; la conoce por contacto directo, pero definitivamente no de manera sistemática. Testimonio de esto resultan algunos de sus papeles de archivo. En ARCAS existen dos carpetas que corresponden a los pre-textos redaccionales de la versión en portugués

6 En el tomo 2 de la correspondencia de Puig a su familia en Buenos Aires aparece una carta fechada por los organizadores en la segunda mitad de 1980. En ella, Puig escribe: "Más buenas noticias todavía: EMPECÉ novela nueva, va a ser complicadita y llevará tiempo, pero me gusta mucho el proyecto, ya estaba dándole vueltas hacía meses pero ahora ya está bien planteado el plan" (Querida familia 317).

"A medida que un cine se valorizaba, su idioma me empezaba a interesar. El inglés, el francés, el italiano. Pensé que el modo de acercarme a esos mundos era estudiar sus idiomas. Leía en esos idiomas. En castellano no leía" (Puig, "Manuel Puig" 69-70). 
y en las mismas pueden verse materiales muy disímiles. Dentro de los que corresponden al primer capítulo -rotulados como "Epílogo" pero de cuyo contenido se puede inferir que se trata en realidad del capítulo con el que se abre el relato- se encuentra solo una hoja suelta escrita a máquina. En ella se lee:

Cuale fui a ultima vez? Há dez anos atraz, oito anos atraz ?. Nao viu mais? nao vi mais. Onde estava ela? em Lages de,....., Estado do Rio. Estava na praca, ahi ao lado da igreja. Mais coisas? ahi dali saímos, ela vim ao meu encontro, tinhamos encontro marcado. Ahí saímos, fuimos até o clube principal, para dancar uma noitada. Mais lances dela? Ali tivemos aquela luz até as duas e meia da madrugada, depois da luz fuimos pelo hotel fazer uma tranzas, entendeu? naquela noite $(A R C A S)^{8}$.

Si bien la hoja no está firmada, su escritura puede ser adjudicada a Manuel Puig y lo que en ella se observa a simple vista es que está escrita, puede decirse, en un "mal" portugués. Este pre-texto redaccional remite a los primeros enunciados de la conversación que pertenecen, por tanto, a la primera cinta grabada. Como se verá más adelante, al parecer se trata de una suerte de ensayo de transcripción de las cintas en vistas ya a construir el relato de la novela en portugués. Puig habría intentado emprender una redacción de la novela trabajando directamente con las grabaciones que hizo de las conversaciones y, al transcribir él mismo la voz del albañil, por no tener en claro las normas de la lengua en que se proponía escribir, cometió varios errores. El escritor argentino presiente esa lengua, la entiende, la escucha, pero no la maneja: desconoce su ortografía ("cuale" por qual, "atraz” por atrás, "tinhamos" por tínhamos, "tranzas" por transas), su gramática ("fuimos pelo hotel" por fomos pro hotel) y está constantemente interferido por el español ("ahí" por $a i$, "fuimos" por fomos). A partir de la observación de este material y puesto que varios de los errores que aquí se detectan no se encuentran en las desgrabaciones pertenecientes al archivo, puede sostenerse que Manuel

$8 \quad$ El fragmento corresponde a la transcripción de la copia dactiloescrita. El uso de negritas señala los agregados en lápiz y con el tachado simple las tachaduras a mano. Se seguirá este criterio de aquí en más para las transcripciones y se especificará cuando sea necesario agregar otros. Ver: "Pre-textos redaccionales" de la versión en portugués, “Archivo Digital Manuel Puig", ARCAS. 
Puig, luego de haber intentado una primera versión, decidió trabajar en la escritura de la novela en portugués utilizando las transcripciones de las cintas realizadas por otros ${ }^{9}$.

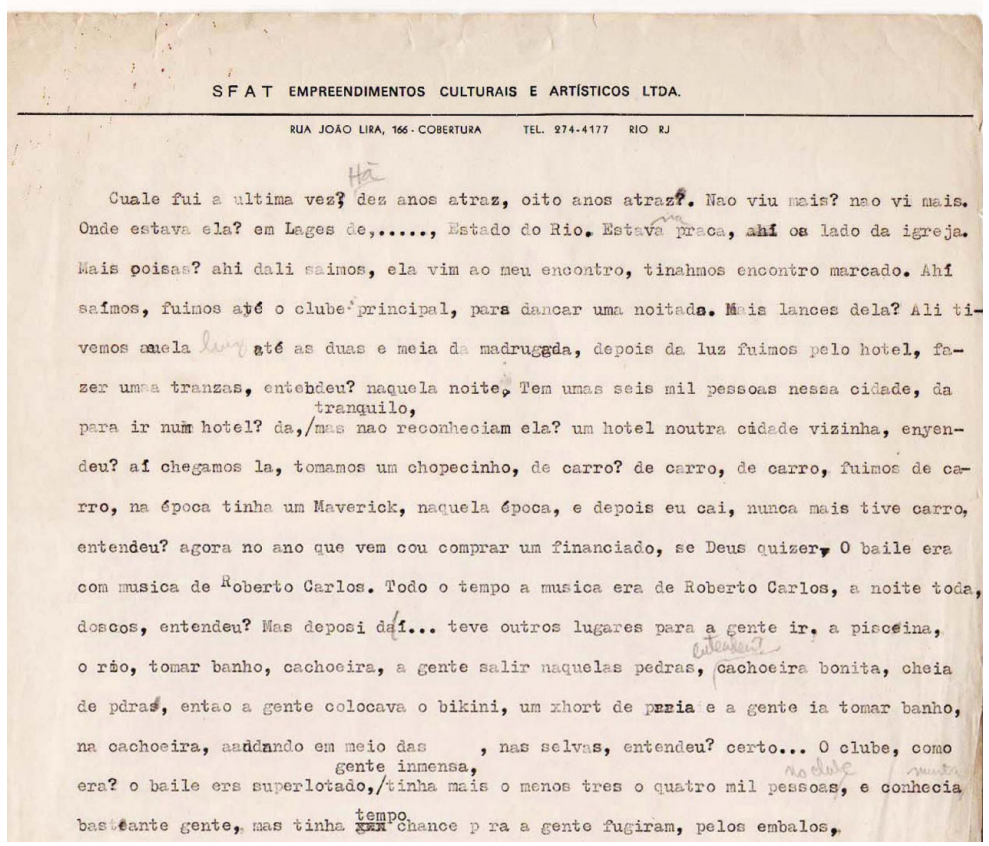

Imagen 1. Primeras líneas de "Pre-texto redaccional" de la versión en portugués correspondiente al comienzo de la novela. "Archivo Digital Manuel Puig", ARCAS.

Con un saber reciente, intuitivo, Puig arma el terreno para la creación de la novela en portugués y en español: "Lo invité a hacer grabaciones de nuestras conversaciones y de ahí salió esta novela que fue escrita, no digo

$9 \quad$ En el "pre-texto redaccional" se ve que aún no han sido realizadas las transformaciones que le darían forma a la novela, tanto en lo que respecta a la composición de la voz del personaje -el modo en que realiza su enunciación-, como en lo que respecta a las modificaciones de la estructura del relato como diálogo/monólogo. Estas cuestiones serán abordadas a continuación. 
en portugués, fue escrita en un dialecto del estado de Río [...] Luego yo mismo traduje la novela al español" (cit. en Romero 345). Si bien ambas novelas fueron publicadas casi a la vez en 1982, como puede verse en la cita, Puig sostuvo que realizó Sangre de amor traduciendo al español la novela en portugués. Es decir, que habría escrito y trabajado primero en el armado de la novela en portugués, para luego, una vez realizada esta, traducirla al españo $1^{10}$. Sin embargo, resultaría forzado y por tanto artificial establecer que la traducción estuvo solo puesta en juego en el pasaje de la novela en portugués a la novela en español, ya que puede decirse que la traducción estuvo implicada en el proceso de escritura de sendas novelas desde el momento en que la conversación se dio entre dos sujetos que no tenían la misma lengua materna y que consideraban la presencia y el vínculo con el otro a partir de esa diferencia. Sostener que Puig tradujo la novela del portugués al español no permite tampoco afirmar que lo que tradujo fue la lengua del albañil sin considerar todas las transformaciones que esta sufre entre el modo en que habló en las conversaciones y el modo en que Puig la dio a leer en la novela.

Las conversaciones de Puig con el albañil fueron grabadas en siete cintas, cada una con dos lados, y fueron transcriptas por otros, tanto a máquina como

10 La diferencia de tiempo entre la publicación de la novela en español y en portugués es de menos de dos meses. En una carta enviada a la familia el 22 de marzo de 1982, Puig anuncia que ese mismo día ha salido la versión en español en Barcelona al tiempo en que da aviso de que ha podido resolver las pruebas de galera de la versión en portugués. El 14 de mayo, en una nueva carta, cuenta que la novela ya está a la venta en Brasil. Ver: Querida familia. Tomo 2. Cartas americanas. New York - Río (1963-1983). Sobre la versión brasileña resta por preguntarse acerca de las modificaciones que pudo haber introducido Barreto Leite, quien un año antes había realizado una nueva traducción de Boquitas pintadas al portugués. Dentro del "Archivo Digital Manuel Puig", de los materiales de trabajo para la novela en portugués, además de las desgrabaciones, se encuentran los pre-textos redaccionales en portugués del décimo capítulo y un dactiloescrito suelto que en el archivo se adjudica al "Epílogo", al que se acaba de hacer alusión. Mediante el cotejo de los pre-textos redaccionales del décimo capítulo -compuesto por fotocopias dactiloescritas con correcciones hechas a mano por Puig- y la versión édita de la novela en portugués puede observarse que las diferencias entre una y otra son pocas y menores (corrección de erratas y uso preposicional). Si bien esto puede dar un indicio, la escasez del material no permite formular una hipótesis sobre la incidencia de la revisión de Barreto Leite en la totalidad de la novela. Asimismo, en sus entrevistas y cartas, Puig no hace mayores referencias al trabajo de revisión del brasileño para Sangue de amor, por lo que además no se conoce con precisión la dinámica con la que trabajaron. Ver: "Pretextos redaccionales" de la versión en portugués, "Archivo Digital Manuel Puig”, ARCAS. 
en forma manuscrita en hojas numeradas ${ }^{11}$. En términos generales, puede afirmarse que Sangre de amor está hecha de las desgrabaciones. De hecho, efectivamente, gran parte de lo que en ella se narra se corresponde -nunca del todo- con lo que cuenta el albañil, pero, para reutilizarlo en función de las búsquedas de la novela, aquello que se cuenta fue también manipulado, recortado, reordenado, reescrito. En el trabajo con las desgrabaciones de las cintas se despliega un amplio arco que va desde la copia textual, la modificación microscópica y llega a la invención de episodios y voces ${ }^{12}$.

En las desgrabaciones, las preguntas y respuestas son referenciadas a partir de las letras P y R, según correspondiera. Quien pregunta, en todos los casos, es Puig; en lo que respecta a las respuestas, si bien la novela se construye en base a lo relatado por el albañil Abelar, lo cierto es que quien responde no es siempre el mismo albañil, ya que en ocasiones $\mathrm{R}$ remite a su hermano, Carlinho, quien también fue interrogado por el autor ${ }^{13}$. Según cuenta el mismo Puig en entrevistas, fue Abelar quien empezó a contradecirse y a dar diferentes versiones de su propia historia. Atraído por esta circunstancia, el autor va a utilizar eso que detectó en el discurso de

11 Las cintas fueron nominadas por Puig de la siguiente manera: A1, A2, B1, B2, C1, C2, D, E1, E2, F1, F2, Zarah1, Zarah2. Ver: "Desgrabaciones", “Archivo Digital Manuel Puig", ARCAS.

12 En cuanto al tratamiento de la narración y su relación con las desgrabaciones, se percibe que, mientras el primer capítulo se corresponde casi por completo con la primera cinta -es decir, el discurso de la narración se corresponde con el discurso del albañil-, a medida que se va cotejando ese trayecto entre las cintas y la novela puede verse que el discurso del albañil será recortado, incluso en mínimos fragmentos, de modo tal que esa primera correspondencia se irá desarmando y complejizando. Esto puede constatarse en el capítulo seis, solo por presentar un ejemplo, que contiene fragmentos que corresponden con las cintas C1, A2 y E2. El trabajo de armado de la novela según esquemas narrativos organizados a partir de episodios puede leerse en las anotaciones en los pre-textos prerredaccionales en donde, en determinados casos, Puig esquematiza el armado de la novela anotando el capítulo, las desgrabaciones transcriptas que va a utilizar, inclusive con el número de página, y el episodio que le interesa resaltar, por ejemplo: \#10, pelo largo, B1/18, A1/19. Ver: "Hojas amarillas" dentro de los "Pre-textos prerredaccionales", "Archivo Digital Manuel Puig", ARCAS.

13 Las conversaciones con Carlinho, quien en la lectura de las desgrabaciones se revelará como el más negro de los dos hermanos, aparecen en función de una pregunta específica sobre la relación entre la potencia física, el hambre, y el deseo: ¿se puede mantener relaciones sexuales si se pasa hambre?, ¿se rinde del mismo modo?, ¿se alcanza el placer? Alguna vez, la intervención de Carlinho es más fácil de percibir puesto que Puig realiza una inscripción con lápiz en la hoja. Ver: "Desgrabaciones", Cinta A2, hoja 11 recto, "Archivo Digital Manuel Puig", ARCAS. 
quien interrogaba -contradicciones, dubitaciones, repeticiones- para armar en la novela una "voz despojada". En el trayecto entre las cintas y la novela, la voz será despojada de la verdad de su relato, en el camino que va de la mentira hacia la locura-Josemar no solo se contradice, lo hace porque está loco-, así como también se la despojará de ese relato como recuerdo de sí mismo, en la medida en que aquello que se recuerda no podrá enunciarse como propio. Esto que sucede entre las desgrabaciones y la novela puede sostenerse al realizarse dos observaciones fundamentales en los materiales de archivo. En primer lugar, puede verse que el diálogo no fue transcripto tal cual, sino que Puig fue manipulando el material escrito de modo que o bien reformuló las preguntas e intervenciones de manera que ocuparan el lugar de las realizadas por la voz evocada como interlocutora -María da Gloria, la madre-, o bien, sin ser formuladas como preguntas ni aparecer de modo explícito, las incorporó al discurso de Josemar como respuestas que se dan al otro, ese otro al que se le dirige la palabra desde el momento en que se habla, se monologa ${ }^{14}$. De este modo, el efecto que se genera es el de la sensación de estar frente a una voz que, al responder a preguntas que nadie formula, revela a cada paso su condición de "mentirosa" y "desquiciada", poniendo en escena una "pérdida" progresiva de una verdad en sus enunciados. En segundo lugar, en lo que respecta a la enunciación de la voz de Abelar, según puede verse en el cuadro de cotejo, entre las desgrabaciones de las cintas y la novela ha tenido lugar una transformación en la que sus declaraciones han pasado de la primera persona del singular a la tercera persona: quien en las entrevistas decía "yo vi”, en la novela dirá "él vio". Así, quien monologa no solo se desdobla en otras voces, sino que, en su propia enunciación, para hablar de sí, lo hace como si hablara de un otro que se encuentra ausente, fuera de la conversación.

14 Por su parte, siguiendo las reflexiones de Alberto Giordano, Sangre de amor correspondido puede pensarse como una puesta en forma de lo que hacen todos los personajes de Puig cada vez que hablan: conversan con Otro - presente o fantasmático- hasta el hartazgo, la mentira o el delirio: "Como se creen en falta frente a los Otros, y esa creencia es un instrumento de tortura que las obliga a confesarse, las voces narradas por Puig sufren una necesidad imperiosa de respuesta, necesitan en todo momento construir una réplica que sea como un lugar sólido en el que poder afirmarse. [...] Los Otros son como un fantasma, una presencia inasible pero apremiante que acecha cada diálogo: están desde antes de que el diálogo comience, presionándolo a comenzar; permanecen en su lugar, inconmovibles, cuando el diálogo concluye, sin importarles cuál haya sido su desarrollo, obligando a recomenzar" (Giordano 200-201). 


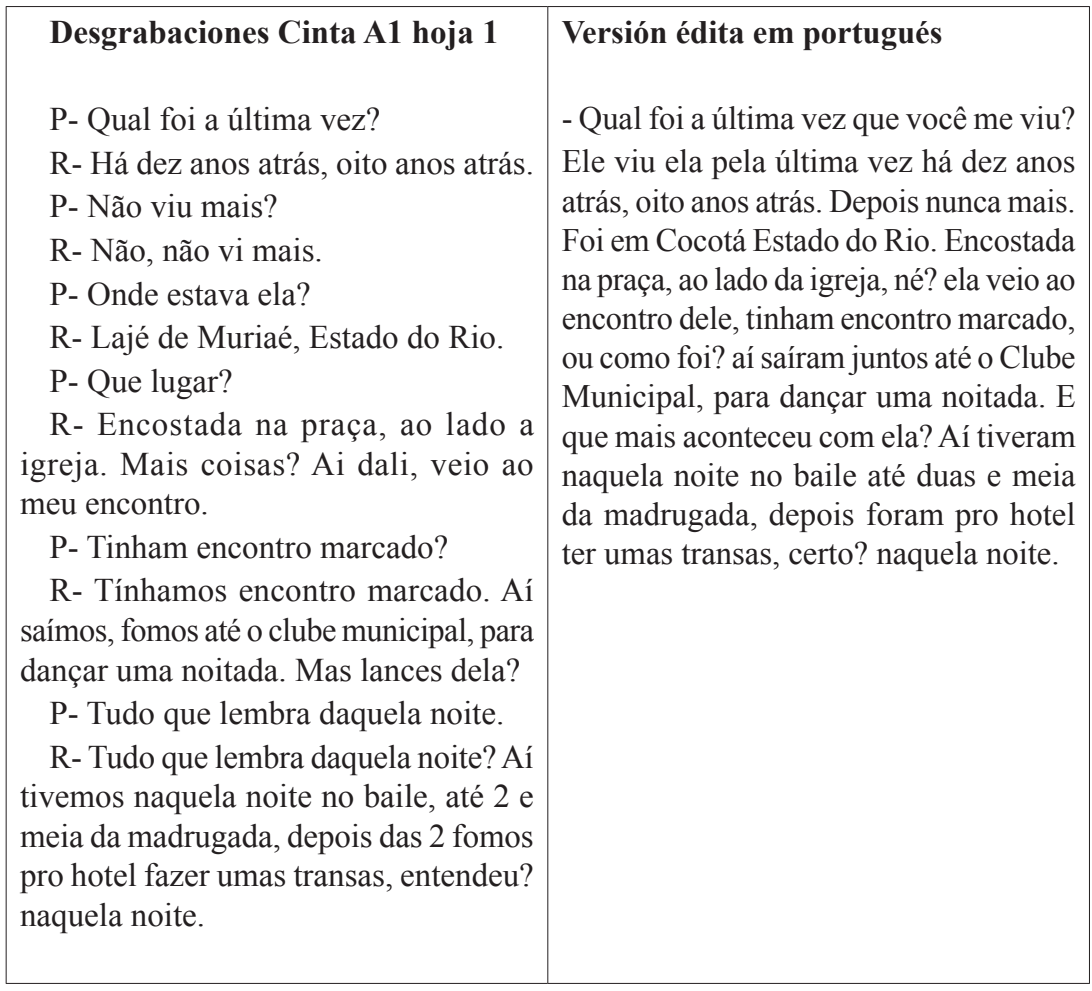

Cuadro de Cotejo 1. "Desgrabaciones" Cinta A1 hoja 1, "Archivo Digital Manuel Puig”, ARCAS y Sangue de amor correspondido edición de 1982, Nova Fronteira, página $9 .{ }^{15}$

$\mathrm{Si}$, a partir de lo anterior, puede afirmarse que Puig no manejaba las normas del portugués de Brasil escrito, que entonces trabajó con las transcripciones realizadas por otros de las grabaciones de la conversación y que, además, las manipuló para construir la voz que quería para su novela; a esta altura,

15 Convenciones de transcripción para los cuadros de cotejo: el señala tachaduras hechas a mano; la negrita señala agregados hechos a máquina; las xxxxx señalan tachaduras hechas a máquina; la cursiva señala agregados hechos a mano. 
deslindar categorías tales como traducción, auto-traducción, copia y, sobre todo, establecer cuál es el original que se traduce resulta complejo. Más que señalar dónde comienza y termina cada una de estas categorías o reparar en el modo en que cada una se fisura por la presencia de la otra, si se quiere pensar la lengua extranjera en la novela en español Sangre de amor, lo que sí puede decirse es que la novela se ofrece al lector de Puig como una "novela traducida": porque en lo que se lee estuvo implicada la traducción, pero, sobre todo, porque lo que se lee se afirma, por los modos en que se muestra, como traducción de algo, nunca como un original ${ }^{16}$.

Así, Sangre de amor es, a la vez, una novela brasileña -por sus temas, sus problemas y su tratamiento, por sus personajes y su emplazamiento-; pero, además, es una "novela traducida" en la que, a pesar de leerse en español, el portugués no deja de escucharse. Ella le revela de manera constante al lector que está frente a algo que no puede pasar como propio, que todo el tiempo reclama que se le reconozca su naturaleza extranjera, insuprimible e indisimulable. La traducción en Puig deviene, tal como lo propone Benjamin, una "forma", donde lo que se busca no es la transmisión de un sentido, sino remitir en ella a las relaciones más íntimas que las lenguas mantienen entre sí $(12)^{17}$. Para eso, será necesario que el escritor fuerce y abra su español de modo de hacer aparecer en él la lengua del otro en tanto experiencia de

16 La novela Sangre de amor correspondido se leerá entonces como "novela traducida", poniendo en juego las teorías de la traducción que permiten realizar esta lectura y las estrategias de traducción correspondientes. Sin embargo, la novela en portugués Sangue de amor no será entendida como su original, ya que en el cotejo se hará referencia tanto a la novela en portugués como a las desgrabaciones. Así, cada una de las novelas será nombrada no como original y traducción sino como versiones del mismo acontecimiento literario. En este sentido, cuando más arriba se sostiene que Sangre de amor se ofrece como traducción y nunca como un original, se está haciendo referencia a un acto por el cual el texto se expone como instancia secundaria. Esto conduce a una puesta en cuestión de los "presupuestos metafísicos" (Derrida "La diferencia [différance]" 14) que ubican al original en un lugar de privilegio al asumirlo como entidad primera y originaria, única y orgánica, siempre igual a sí misma de la que la traducción sería una mera réplica siempre incompleta.

17 Aquí, hacer referencia la concepción benjaminiana de traducción como "forma" implica tomar no solo su ensayo escrito en 1921 y publicado en 1923 como prólogo a la traducción que hiciera de "Tableaux Parisiens" de Charles Baudelaire, sino también las posteriores lecturas que de él se hicieron para continuar reflexionando en esa misma línea sobre la traducción, en particular, las realizadas en Francia por los teóricos: Maurice Blanchot, Jacques Derrida y Antoine Berman. 
lo extranjero (Berman, "La traducción como experiencia" 4), es decir, su escucha de la lengua del albañil tal como ha tenido lugar en el intercambio.

\section{NOVELA EN ESPAÑOL, NOVELA TRADUCIDA}

En una entrevista, que se encuentra entre los materiales del "Archivo Digital Manuel Puig" correspondientes a la década del ochenta, el escritor se aproxima a la noción de traducción que puso en juego en el armado de Sangre de amor:

Y, ¿qué quedó de la motivación original, el lenguaje del albañil?

- Ese fue otro problema. Las grabaciones estaban hechas en portugués $y$, al intentar aprovecharlas en el texto, me di cuenta de que ese lenguaje no se podía corresponder a ningún modelo reconocible del castellano. No podía traducirlo al lunfardo, al lenguaje coloquial de Buenos Aires o al modelo popular pampeano. No tenía otra salida que inventar un lenguaje ficticio que pudiese corresponderse con la imagen verbal del personaje $(A R C A S)^{18}$.

En tanto Puig se propone que la singularidad de la voz del albañil perviva en la novela en español, la traducción no podrá llevarse a cabo como la búsqueda de equivalencias. A diferencia de lo que sí podía hacer a la hora de subtitular películas, en donde se esforzaba por adaptar la idiosincrasia entre una cultura y otra en el marco de la traducción ${ }^{19}$, el escritor asegura que no existe un modelo lingüístico argentino que se corresponda con la lengua del albañil tal como la escuchó. Si la novela se da a leer como "traducida", esto ocurre porque, al traducir, Puig decide detenerse y hacer aparecer en su lengua materna la lengua extranjera a partir de la cual armó la novela.

Entre la novela en portugués y la novela en español hay una diferencia tal que hace que la primera se ofrezca como "transcripta" mientras la segunda como "traducida", y esa diferencia puede verse en el modo en que da a leer

18 "Diálogo con Puig", entrevista localizada en "1971-1985. Década del 80 (DDO)", correspondiente a "Documentos y para-textos", "Archivo Digital Manuel Puig", ARCAS.

19 Sobre la traducción de subtítulos, Puig comenta con María Esther Giglio: "Hacía traducciones de subtítulos, que no es fácil. Hay que acertar los diálogos guardando la esencia, adaptar el humor de un país al otro y otras cosas" (cit. en Romero 237). 
la voz de Josemar como una voz oral: “Aí tiveram naquela noite no baile até duas e meia da madrugada, depois foram pro hotel ter umas transas, certo? naquela noite" (Sangue de amor 9) / "Estuvieron en el baile hasta las dos y media de la madrugada, después se fueron a un hotel a hacer sus cosas ¿está claro? aquella noche" (Sangre de amor 9). La voz de Josemar en la novela en portugués presenta un conjunto de rasgos que remiten a la oralidad: lo que se lee es sin dudas una voz que habla, pero es también un habla "transcripta". Esto se debe a que algunas de esas marcas de oralidad generan una ruptura con la norma escrita: tal es el caso, por ejemplo, de la contracción de la preposición "para" con el artículo "o", "pro", en el fragmento citado arriba. Ellas reenvían a la instancia de transcripción de las cintas de la novela -y, de hecho, mediante el cotejo puede verse que están presentes en las desgrabaciones- pero además marcan la voz de Josemar como perteneciente a un estrato social, geográfico y cultural: el habla del campesinado pobre del interior de Brasil ${ }^{20}$. Por su parte, cuando se lee la novela en español, si bien la voz de Josemar se presenta siempre desde la oralidad, Puig limpia esa voz de las marcas que remiten a su transcripción y a su inscripción; lo hace justamente porque no hacerlo supondría la creencia de que existe algún habla -el lunfardo, el lenguaje coloquial de Buenos Aires, el modelo popular pampeano-que le corresponde. Al escribir esa voz en español, decide desmarcarla, no para neutralizarla ${ }^{21}$, sino para asumir su intraducibilidad y, saliéndose del juego de las equivalencias, mantener su singularidad ${ }^{22}$.

20 Así también, la voz de la madre de Josemar que se lee en el capítulo onceavo aparece aún más marcada, con rasgos que la voz de Josemar no presenta, enfatizando su marginalidad. En ella la oralidad se transcribe a partir de marcas más radicales en cuanto a la ruptura de la norma escrita: num por não, mulhié por mulher, mió por melhor, té por até, entre otras. Es importante aclarar respecto de este capítulo y de la voz de la madre que no se encuentran en las desgrabaciones a las que se tiene acceso. Puig pudo o bien haberla creado sin ningún tipo de modelo, o bien pudo haber existido algún modelo del que no se pueda dar noticia según los materiales de archivo.

$21 \quad$ Aquí se hace referencia al término "neutralizar" en el sentido que cobra dentro de los estudios de la traducción, una lengua artificial útil para cualquier hablante, como koiné. Más adelante en el trabajo se retomará esta cuestión.

22 En el ensayo de Benjamin, la traducibilidad de un texto original compone una paradoja: es aquello -el "núcleo esencial", en palabras del filósofo alemán-más intraducible del texto, lo que no puede alcanzarse nunca totalmente y escapa a toda transmisión de sentido y, a la vez, el motivo por el cual ese texto es traducido, lo que lleva al traductor a hacerlo. Sobre la traducción y la traducibilidad, ver: Benjamin La tarea del traductor y la lectura que 


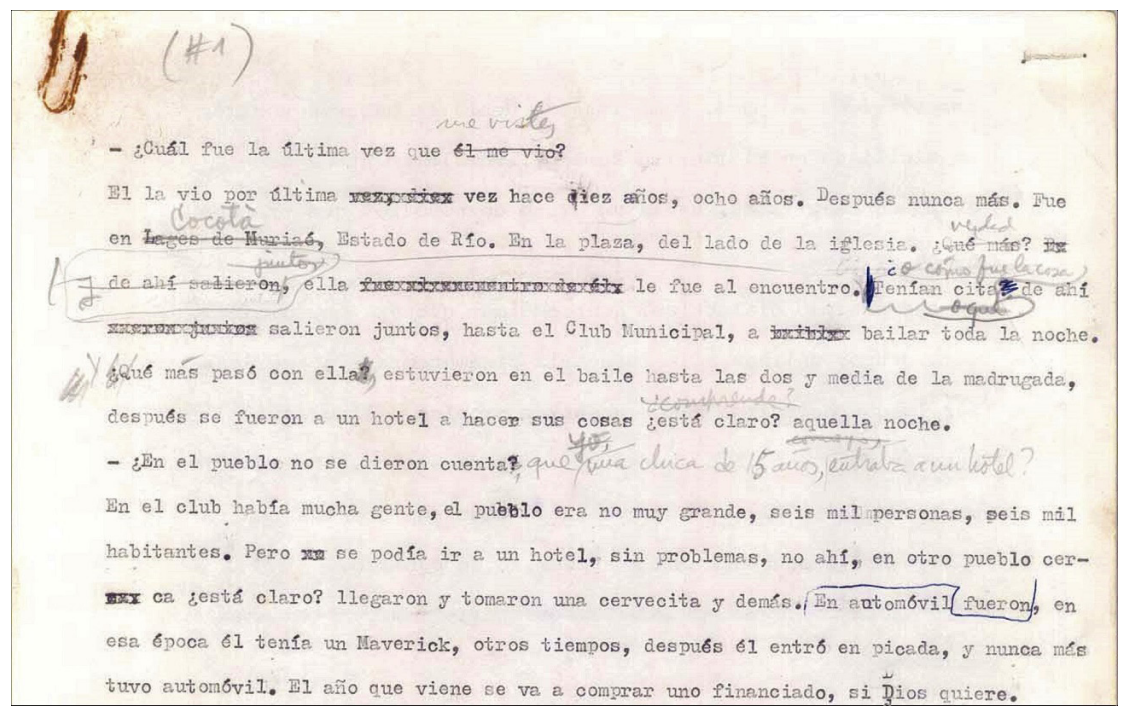

Imagen 2. Primeras líneas de los "Pre-textos redaccionales" correspondiente a la primera versión de la novela en español, "Archivo Digital Manuel Puig", ARCAS.

Así puede leerse lo que sucede con el enunciado que abre la conversación entre la versión édita en portugués, “- Qual foi a última vez que você me viu?", la primera versión de la novela dentro de los pre-textos redaccionales en español, “¿Cuál fue la última vez que él me vio me vistes?” y la versión édita en español “- ¿Cuál fue la última vez que me viste?" en la pregunta que le da inicio. Si se observa lo que sucede con ese enunciado en la versión publicada de la novela en español, puede verse que la "-s" presente en la palabra "vistes", una partícula que en verdad implica un error en la conjugación de la segunda persona del pretérito perfecto del indicativo y que es por lo demás muy común, sobre todo en la oralidad, es eliminada.

En la incorporación y posterior eliminación de esa "-s", que remitiría a cierta oralidad de sustrato popular de la lengua, Puig realiza un gesto mínimo pero decisivo respecto de la construcción de una lengua para su novela.

de él hizo Jacques Derrida en “Torres de Babel”, ensayo incluido en Psyché. Invenciones del otro. 
Allí, se corrobora que decide desmarcar su lengua de una posible remisión a un hablante argentino, evitando romper las normas de la lengua escrita en español, para en cambio moverse por sus zonas no normadas. Al concebir que el artificio de las equivalencias es siempre una manera de ocultar aquello que mantiene al otro en su otredad, Puig, a partir de diferentes estrategias de traducción, hace del español de su novela un territorio donde mostrar el modo en que lo otro puede manifestarse en lo propio. Así, esa lengua extraña -por los forzamientos a los que se verá sometida- será la respuesta a la imposibilidad de traducir que se plantea Puig desde el principio, y será el modo de señalar -solo señalar- aquello que tuvo lugar en el encuentro entre su lengua y la del albañil.

\begin{tabular}{|c|c|}
\hline Primera versión pre-texto redaccional & Versión édita en español \\
\hline $\begin{array}{l}\text { - ¿Cuál fue la última vez que él me vio } \\
\text { me vistes? } \\
\text { El la vio por última xxxxxxxxx vez hace } \\
\text { diez años, ocho años. Después nunca más. } \\
\text { Fue en Eage de Murriaé, Cocotá, Estado } \\
\text { de Río. En la plaza, del lado de la iglesia. } \\
\text { ¿ Quté más?verdad. xx y de ahŕ́ salieron } \\
\text { juntos, ella xxxxxxxxxxxxxxxxxxxxxxx le } \\
\text { fue al encuentro. Tenían cita ? o que ¿o } \\
\text { cómo fue la cosa de ahí xxxxxxxxxxxxx } \\
\text { salieron juntos, hasta el Club Municipal, a } \\
\text { xxxxxxx bailar toda la noche. Y ¿̇qué más } \\
\text { pasó con ella?, estuvieron en el baile hasta } \\
\text { las dos y media de la madrugada, después } \\
\text { se fueron a un hotel a hacer sus cosas } \\
\text { ¿está claro? ¿comprende? aquella noche. }\end{array}$ & $\begin{array}{l}\text { - ¿Cuál fue la última vez que me viste? } \\
\text { Él la vio por última vez hace diez años, } \\
\text { ocho años. Después nunca más. Fue en } \\
\text { Cocotá, Estado de Río. En la plaza, del } \\
\text { lado de la iglesia ¿verdad? ella le fue al } \\
\text { encuentro, tenían cita ¿o cómo fue la } \\
\text { cosa? de ahí salieron juntos, hasta el Club } \\
\text { Municipal, a bailar toda la noche. ¿Y qué } \\
\text { más pasó con ella? Estuvieron en el baile } \\
\text { hasta las dos y media de la madrugada, } \\
\text { después se fueron a un hotel a hacer sus } \\
\text { cosas ¿está claro? aquella noche. }\end{array}$ \\
\hline
\end{tabular}

Cuadro de Cotejo 2. Transcripción de "Pre-texto redaccional" primera versión correspondiente a la versión en español, "Archivo Digital Manuel Puig", ARCAS y Sangre de amor correspondido edición de 1998, Seix Barral, página 9. 
Para que la novela como "novela traducida" se manifieste en tanto experiencia de lo extranjero, en el sentido en que lo considera Berman, es decir, como apertura de relación con lo otro sin intentar reducir su extrañeza e incluso revelando aquello que tiene de más singular ${ }^{23}$, Puig parece ignorar -si no ir a contramano- las traducciones inclinadas a velar por la fidelidad al sentido. Estas últimas trabajan con vistas a lograr en la lectura de una obra traducida que aquello que se lee suene como si fuese lo que el autor habría escrito si lo hubiera hecho en la lengua de destino. Para lograr esto, el axioma principal sostiene que se debe traducir la obra extranjera de modo que no se "sienta" la traducción ${ }^{24}$. Este axioma en función del sentido supone además la desaparición, el borramiento de las marcas tanto del acto de traducción en tanto tal como del trazo del traductor: estos deben invisibilizarse, volverse transparentes, como si lo que se traduce no hubiera estado nunca, de hecho, escrito en "otra" lengua ${ }^{25}$. Puig, por el contrario, llamará la atención sobre la traducción ya que la lengua portuguesa -el modo en que Puig la escuchó del albañil y el modo en que la configuró en el personaje de Josemar- se hace ver desde una transparencia que se juega en su signo inverso: no se trata de

23 "La experiencia de lo extranjero" es una expresión que utiliza Heidegger para definir parte de su experiencia de lectura de la poesía de Hölderlin y que Antoine Berman retoma en su texto "La traducción como experiencia de lo/del extranjero" para sostener que esa lectura revela la esencia misma de la traducción en tanto muestra la obra en su pura extrañeza al tiempo en que desarraiga también a la obra de su propio suelo. Ese sería, según Berman, "el poder más singular del acto de traducir: revelar lo más original de la sustancia de la obra extranjera, lo más profundo, así como lo más "distante"” ("La traducción como experiencia" 4).

$24 \quad$ La traducción de la letra, además de ser fundamentalmente una traducción de una forma, en el sentido benjaminiano, es para Berman un modo de traducir que se opone a los modelos tradicionales -en su caso particular, franceses-, los cuales serían etnocéntricos, hipertextuales y platónicos. Por oposición, la manera de traducir la letra sería, simultáneamente ética, poética y pensante y sus modos estarían en pos de una fidelidad a la forma en lugar de la fidelidad al sentido, puesto que, según Berman, la captación de este último: "no libera al sentido en un lenguaje más absoluto, más ideal o más 'racional': lo encierra simplemente en otra lengua, postulada es cierto como más absoluta, más ideal y más racional" (La traducción y la letra 35$)$.

25 Este uso de la idea de transparencia es el que utiliza Lawrence Venuti al construir la historia de la traducción en el ámbito anglosajón: "The illusion of transparency is an effect of fluent discourse, of the translator's effort to insure easy readability by adhering to current usage, maintaining continuous syntax, fixing a precise meaning [...] The more fluent the translation, the more invisible the translator, and, presumably, the more visible the writer or meaning of the foreign text" (The translator's Invisibility 1-2). 
que el traductor y su traducción se vuelvan transparentes a un sentido, sino que, haciéndose visibles en tanto tales, recurran a operaciones por las que su lengua pueda "transparentar" una lengua otra ${ }^{26}$. Alojar una lengua extranjera implica necesariamente operar una violencia tal sobre la propia lengua que la vuelve extraña.

Resulta difícil, sino imposible, agotar cada una de las razones por las cuales una lengua se vuelve extraña por la traducción. Aun así, se señalarán algunas de las operaciones por las que esa extrañeza se puede manifestar. Tal es el caso de lo que sucede con la no traducción de los nombres propios, con el uso de los pronombres de tercera persona y con la presencia de sufijos diminutivos.

Uno de los primeros gestos a partir del cual puede advertirse que se está ante una novela extranjera radica justamente en la no traducción de los nombres propios de los personajes. Para el armado de la novela, Puig cambió los nombres de los protagonistas de la historia relatada por el albañil: Abelar pasa a llamarse Josemar y su novia, Maria do Socorro, se transforma en María da Gloria, y así los mantuvo tanto en la versión en portugués como en la versión en español. Si bien la grafía se adapta en las tildes, Maria da Glória en portugués y María da Gloria en español, se percibe que su sonoridad pervive inalterable y, en la versión en español, señala su origen al lector ${ }^{27}$. Por su parte, otros nombres propios de la novela -hermanos, madre, amantes- sin ser traducidos al español, varían entre Sangue de amor y Sangre de amor. Tal es el caso, por ejemplo, de la maestra Aneci, que en Sangre pasa a llamarse Valseí. Tal alternancia ocurre en función del lector y del contexto de publicación: si Puig los cambió en primera instancia eso se debió a que no quiso generarle un problema al albañil, y, al tener luego como horizonte otro público, en la versión en español volvió sobre los nombres

26 En este sentido, el ensayo de Benjamin permite considerar la transparencia de una manera completamente diferente. La transparencia de la traducción está en función de dejar ver el original, no hacerle sombra y, por tanto, ese transparentar implicará no la fluencia, sino más bien el corte que permita la aparición de lo otro: "El significado de la fidelidad, garantizada por la literalidad, es más bien el hecho de que a través de la obra consiga escucharse el enorme anhelo de la culminación de las lenguas. La verdadera traducción es transparente, no oculta el original, no le hace sombra, sino que deja que la lengua pura, fortalecida por así decirlo por hallarse en su propio medio, caiga con plenitud sobre el original" (24).

27 En los pre-textos redaccionales se puede corroborar el cambio en la grafía. 
de las $\operatorname{cintas}^{28}$. Además, la novela se adhiere a la lengua extranjera en los nombres propios de un conjunto de referencias geográficas -Lajé de Muriaé, en las cintas, y Cocotá, en las novelas-, localizables en el mapa brasileño, y referencias culturales - la camiseta Volta ao mundo, los cruzeiros, el cantante de boleros Roberto Carlos-, que, lejos de aclimatar, pueden leerse como parte del conjunto de estrategias de traducción extranjerizante, que llaman la atención sobre el carácter "traducido" del texto" 29.

Como se dijo, según puede verse en los archivos, en el camino que va de las cintas a la novela, Puig pasó lo que decía el albañil de la primera a la tercera persona en pos de la construcción de una "voz despojada": tanto de la verdad de su relato como de su relato como recuerdo de sí mismo. En la novela en portugués, ese pasaje implicó la reposición cada vez y en toda oración de la presencia del pronombre "ele" o "ela", ya que así lo exigen las normas de la lengua portuguesa, la cual requiere -al igual que otras lenguas como el francés, el inglés o el alemán- colocar el sujeto pleno en la oración, a pesar de que su presencia ya esté inscripta en la desinencia verbal: "Ele viu ela pela última vez há dez anos atrás, oito anos atrás" (Sangue de amor $9)^{30}$. En el caso del español, la disposición es la contraria: el sujeto tiende a

Dice Puig: "Josemar es un nombre muy común en Brasil, pero no es el nombre de él. Yo cambié todo para que él no tuviera problemas. Como él contaba cosas reales cambié todos los nombres, incluso hubo ciertas cosas para despistar, en vez de tal ciudad, tal otra, para no crearle problemas" (cit. en Romero 337). Esta no traducción de los nombres propios se vincula directamente con la no traducción de las referencias a la geografía brasileña en la que se emplaza la acción. Pero aquí, ambas novelas emplazan su acción en Cocotá, a diferencia de las cintas en las que se dice que todo ocurre en Lajé de Muriaé. Sin embargo, estos cambios no suponen la creación de un lugar inexistente, desrreferenciado, como Coronel Vallejos, sino que más bien se trata de un corrimiento desde el interior del Estado de Río de Janeiro a un barrio en Ilha do Governador, en la zona costera.

${ }_{29} \quad$ Según Venuti, las estrategias de traducción implicadas desde el momento es que se escoge un texto extranjero a ser traducido, desde la antigüedad, pueden dividirse en dos grandes categorías: estrategias de domesticación y de extranjerización. Esta última, cercana a los planteos éticos de Berman en torno a la traducción como experiencia de lo extranjero, es el tipo de estrategia a la que Puig se aproxima en la escritura de la novela en español. Venuti continúa: "From its origins in the German tradition, foreignizing translation has meant a close adherence to the foreign text, a literalism that resulted in the importation of foreign cultural forms and the development of heterogeneous dialects and discourses" ("Strategies of Translation" 242).

30 En su artículo "Pero ¿qué gramática es ésta? Los sujetos pronominales y los clíticos en la interlengua de brasileños adultos aprendices de Español/LE", la investigadora Maia González sostiene: "De forma sintética, se puede decir, siempre a partir de los varios estudios 
elidirse puesto que es una lengua de sujetos nominales predominantemente nulos. Cualquier traducción del portugués al español requeriría, si se rige por las normas de aceptabilidad de la lengua de destino, la elisión del sujeto pronominal. Puig, por el contrario, decide mantener la presencia del pronombre "él" o "ella" y de esa manera arma una lengua extraña, un español "enrarecido":

Mas nada! ele não tem pra comprar outro maço de cigarros, e apenas três lhe sobram para toda a noite. Mas ele vai ascender mais um outro. Ele tinha aproximadamente onze anos por aí, quando ele descobriu. Ele viu tudo, chegou em casa, contou tudo pra mãe dele" (Sangue de amor 34) [El resaltado es nuestro].

"Pero nada. Él no tiene para comprarse otro paquete de cigarrillos, y ya le quedan tres apenas, para toda la noche. Y va a encender otro más. Él tenía unos once años cuando descubrió todo. Vio todo, volvió a casa y le contó a la madre" (Sangre de amor 38) [El resaltado es nuestro].

En los pasajes citados puede verse que Puig, de las cuatro oraciones en portugués en las que aparece el pronombre de tercera persona, en la versión en español los repone no en todas, sino en dos de ellas -lo que evidencia, además, el carácter deliberado de la decisión-. De este modo, apunta a un equilibrio que lleve la lengua a su enrarecimiento, evitando volverla extravagante, y hace que toda vez que aparece ese pronombre en la voz traducida de Josemar se instale una doble extrañeza: del personaje respecto del propio discurso y de la lengua traducida al hacer sonar en ella la lengua extranjera. El pronombre traza una distancia, corta la fluidez de la lengua y le impone, de nuevo, un sonido y un ritmo otros ${ }^{31}$. En las primeras páginas

consultados, que mientras el PB es una lengua de sujeto pronominal predominantemente pleno y que privilegia las categorías vacías o las formas tónicas para la expresión de los complementos, el E es claramente una lengua de sujetos pronominales predominantemente nulos y complementos clíticos abundantes, a veces duplicando (o quizás duplicados por) una forma tónica. Esa diferencia fundamental - con todos los efectos que de ella se derivan- se irradia, en los dos casos, y afecta a una serie de construcciones correlacionadas en cada una de las lenguas, hecho que parece reforzar la conveniencia de un abordaje paramétrico" (247).

31 Para Venuti, la condición de fluidez en la lectura es fundamental en las propuestas de traducción como domesticación, ya que permite obviar la presencia de traducción, el proceso de traducción y, por tanto, la lengua traducida, en nombre de un principio de legibilidadinteligibilidad, produciendo la ilusión de un mejor acceso al sentido del original: "Under the regime of fluent translating, the translator works to make his or her work 'invisible', producing 
de la novela se lee: "Então eles ficavam, vinha cafezinho, bife, aqueles bifões que ele gosta, vinham essas coisas todas. Saía normalmente à meia noite de lá. Da casa dela, da casa da mãe dela. Somente ele e ela, e a mãe, e a avó" (Sangue de amor 10) [El resaltado es nuestro]. / "Y ahí se quedaban, a él le servían cafecito, o un bife, de aquellos bifazos que a él le gustan, todo eso. Él se quedaba como hasta las doce de la noche. En la casa de ella, de la madre. Estaban él y ella, y la madre, y la abuela" (Sangre de amor 10-11) [El resaltado es nuestro]. A diferencia de lo que pasaba en los pasajes anteriores, en estas citas puede verse que en la versión en español la presencia de los pronombres personales "él" y "ella" -resonando también en los posesivos pospuestos "de + pronombre personal": "de ella"- es aún mayor de la que aparece en la versión en portugués. Este exceso manifiesta nuevamente que Puig no copió tal cual, palabra por palabra, lo que el albañil decía en otra lengua, sino que lo que puso en juego fue una traducción "literal", entendida como traducción de una "forma": utilizó aquello que en la otra lengua le sonaba como ajeno a la propia para mostrar en esta última un sonido que viene de otro lugar, una sintaxis otra, pero que, por medio de un acto de violencia, la propia lengua puede alojar forzando la frontera de la norma -aunque sin cruzarla completamente- y tocando su propio límite de aceptabilidad.

La última operación a tener en cuenta aquí es la que tiene lugar en la presencia y el uso de los diminutivos en la versión en español. Como se sabe, existe en torno de la lengua portuguesa de Brasil un imaginario que sostiene que cuando un extranjero la escucha percibe en ella cierta musicalidad. Uno de los sonidos que más se asocia a la idea de musicalidad de la lengua brasileña es el que produce el uso de los diminutivos que, por regla general, en portugués se arman con el sufijo “(z)inho/(z)inha”. Estos aparecen en la voz del albañil, según puede leerse en las desgrabaciones, y Puig los recupera en la novela en portugués, en función de esa construcción de una "novela transcripta", pero también entre una y otra versión. Si bien en el español hablado su presencia no es infrecuente, no es, sin embargo, un sonido del que pueda decirse que caracteriza o identifica al español rioplatense y aparece en una medida mucho menor que en el portugués brasileño hablado. Por eso, cuando estos aparecen en el español de la novela de manera reiterativa y acumulativa, y por la cercanía en el sonido con el que se arman en una y

the illusory effect of transparency that simultaneously masks its status as an illusion: the translated text seem 'natural', i.e., not translated" (The translator's invisibility 5). 
otra lengua -en español los diminutivos también se construyen a partir de un sufijo compuesto por las mismas vocales i-o e i-a ["(c)ito/(c)ita"]-, lo que señalan es que provienen de otra lengua. Así, la traducción se mueve por espacios de inestabilidad que no dicen que lo que se lee está mal, sino que, a lo sumo, lo que se lee "suena raro". Se trata, siempre, de un borde de la norma, donde la diferencia entre la versión en portugués y la versión en español se lee en la medida en que Puig maneja el equilibrio entre los modos en que dan a leer las versiones. En el ejemplo que sigue, en función de ese equilibrio, el escritor traduce los diminutivos no en todas las ocasiones, sino solo cuando estos están adheridos a los sustantivos; cuando en portugués aparecen en los adjetivos, prefiere evitarlos:

Quando o passarinho fosse bom, de gaiola, cantava, ele tinha o maior carinho. Quando fosse passarinho bobo, aquele passarinho ruim, ele arrancava pena, deixava ele peladinho e soltava. Aí um dia o pai dele viu, normalmente o pai via passarinho pelado andando nuzinho, "Porra! Não faz isso com o bicho, rapaz, deixa os bichinhos em paz!" (Sangue de amor 29).

Si el pajarito valía algo, si era de jaula y cantaba, él le tenía el mayor cariño. Si era un pajarito bobo, y feo, le arrancaba las plumas, lo dejaba pelado, y lo soltaba. Ahí un día lo pescó el padre, ya muchas veces había visto pájaros pelados que andaban desnudos, "Carajo, no le hagas eso a un pobre animal, hay que dejar a los animalitos en paz!" (Sangre de amor 32).

Cuando Puig escribe Sangre de amor como una "novela traducida", lo hace abriendo la lengua materna al portugués en el vínculo particular entre ambas lenguas. Al reponer en cada oración el sujeto pronominal o hacer sonar un diminutivo, abre su lengua para que la voz del otro aparezca volviendo extraña la propia, afirmando, así, en ese encuentro, que traducir es imposible y que es esa imposibilidad-como acercamiento-la que lo mueve a hacerlo ${ }^{32}$.

32 La traducción como imposibilidad y deseo es esbozada por Jacques Derrida en su ensayo "Torres de Babel". Allí, sostiene que la traducción "no llega jamás a alcanzar, a tocar, a pisar ese reino [el de la conciliación de las lenguas al que hace referencia Walter Benjamin]. Pero una promesa no es algo inconsistente, no solo se caracteriza por lo que le falta para que se cumpla. Como promesa, la traducción es ya un acontecimiento, y la firma decisiva de un contrato" (240). 
A la inversa de lo que considera Dos Santos Menezes cuando afirma que Puig "procurou adotar no texto em espanhol uma variante que seguisse um movimento de koinização" (34), es decir, que escribió motivado por la búsqueda de una lingua franca, Sangre de amor afirma que la traducción se funda en la diferencia y se mueve por el deseo de acercarse al otro en tanto otro, y de insistir sobre ese deseo en la escritura ${ }^{33}$.

Finalmente, si, como afirma Lawrence Venuti, todo lo que sucede en la traducción solo puede medirse en referencia al impacto que genera en los valores de la lengua de la cultura de destino ${ }^{34}$, la novela traducida no deja tampoco de señalar en su interior que se está frente a un texto que forma parte del conjunto reconocible como la literatura de Manuel Puig. De hecho, es el punto de partida desde el cual se presenta al lector para que este luego la reconozca como una "novela traducida", es decir, diferente, en algún punto, del resto. Así, junto a algunas claves narrativas que remiten a un diálogo con Boquitas pintadas, en la lengua de Sangre de amor aparecen otras señales con las que el lector es devuelto a la literatura de Puig:

O baile estava superlotado, gente à beça, três a quatro mil pessoas. Eles conheciam muita gente, bastante gente, mas dava tempo, chance pra fugir para os embalos. Ela tinha esperado ele na praça ou na saída da igreja, que ela era muito católica. Então normalmente ela esperava na porta da igreja. Oito horas da noite, ou ia pra casa dela ou senão pra casa de uma tia (Sangue de amor 10) [El resaltado es nuestro]. El baile estaba abarrotado de gente, tres mil o cuatro mil personas. Ellos dos conocían a mucha gente, tanta, pero daba tiempo, ya se iba a presentar la ocasión de mandarse a mudar. Ella lo había esperado en la plaza, esperaba generalmente ahí, o a la salida de la iglesia porque era muy católica. Si todo salía bien lo esperaba todas las noches en la puerta de la iglesia. A las ocho de la noche generalmente. Y de ahí rumbeaban al final para la casa de ella, o si no para la casa de una tía (Sangre de amor 10) [El resaltado es nuestro].

33 Maurice Blanchot, siguiendo el ensayo de Benjamin, dice acerca del traductor: "El traductor es un escritor de una singularidad original, precisamente allí donde parece no reivindicar ninguna. Es el dueño secreto de la diferencia de las lenguas, no para abolirlas, sino para utilizarlas, a fin de despertar, en la suya, por los cambios violentos o sutiles que él le ocasiona, una presencia de lo que hay de diferente, originalmente en el original" (57).

34 "Strategies in producing translation inevitably emerge in response to domestic cultural situations" (Venuti, "Strategies of translation" 240). 
En el fragmento anterior se lee una secuencia narrativa que acopla cada una de las respuestas que el albañil le fue dando a Puig en torno a la última noche en que vio a María do Socorro en el baile del pueblo. El relato del baile no es nuevo en Puig, es central en Boquitas pintadas y en torno a él se constelan ciertos elementos clave: la vestimenta de los novios, la música, las canciones que se bailan y el tópico del retorno, en el que se recuerdan las caminatas de Juan Carlos o de La Raba y Pancho. Por eso, porque la literatura que se lee es la literatura de Puig, la traducción se encarga de hacerla resonar en algunas expresiones: lo que en la versión en portugués fue "fugir para os embalos" será en la versión en español "mandarse a mudar" y el verbo "ir" aparecerá como "rumbear"; expresiones que bien pudieran leerse en la novelística de Puig dichas por cualquier Don Juan de pueblo de provincia en la década del treinta.

\section{EL FINAL: LA FOTO POSTAL}

Como en otras novelas del autor, en Sangre de amor hay un momento en que la narración habla de sí misma. Se trata de una escena breve pero contundente donde se reflexiona acerca de la naturaleza del relato y su funcionamiento. En ella, se lee la voz de Josemar en el capítulo doce, momentos antes de que revele que no ha consumado su encuentro con María da Gloria debido a que su madre intervino impidiéndolo:

La María da Gloria nunca vio la foto, de la madre de él cuando era criaturita, de ocho años, una postal en colores, no era foto de ella misma, porque en la familia eran pobres y en el campo no sacaban fotos, era una postal comprada pero la madre de él, un día la vio y se la pidió a alguien que la tenía, porque pensó que era igual a ella misma cuando era una criatura. Él ya se la pidió, y si la madre le pregunta otra vez qué quiere que le deje de recuerdo él no se lo va a decir otra vez, si ella se acuerda bien y si no a otra cosa, qué joder (Sangre de amor 223-224).

En la escena se narra el modo en que operan la verdad y el recuerdo a lo largo de toda la novela: esa postal en la que no aparece la madre es, sin embargo, una imagen de la madre que le permite a Josemar recordarse y recordarla. No se dice de la postal de una niña que sea una foto de la madre, 
eso no tiene importancia, porque lo que importa es poder narrar un recuerdo, incluso aunque el mismo relato sea una testificación de su despojo. Del mismo modo, el personaje recuerda a María da Gloria y se recuerda a sí mismo a partir de un hecho que nunca tuvo lugar, pero que funciona como motor de la conversación. Eso fue lo que escuchó Puig mientras el albañil relataba y lo que lo llevó a interesarse, además de por su habla, por su historia. Lo que le fue contando perdió rápidamente el estatuto de verdad, pero, aun así, lo que contaba y el modo en que lo hacía le dieron una novela y un personaje.

Esta misma escena puede devenir para la novela en español, si se la piensa desde su proceso de escritura y en particular desde el lugar que tuvo allí la lengua extranjera, en un momento "traductológico" -en el sentido en que entiende Berman la traductología, es decir, como "la reflexión de la traducción sobre ella misma a partir de la naturaleza de su experiencia" ( $L a$ traducción y la letra 18)-. Traducir no fue para Puig dar a leer una lengua por otra, sino que, abriendo la propia lengua y llevándola a la extrañeza por la presencia del otro en tanto otro, puso en juego una escritura que mostrara la presencia de la traducción, que se dejara leer como tal, una postal que tiene para decir de sí misma que no es la otra-lengua-, pero que puede albergar en su imagen el recuerdo del encuentro con lo otro.

Durante el transcurso de los casi nueve años que Puig residió en Brasil, recurrió al portugués en diversas instancias de escritura. Entre su producción dramática, por ejemplo, donde la lengua extranjera funcionó como mediación para un público determinado, se puede mencionar la comedia musical Gardel, uma lembraça. Estrenada en 1988, esta obra fue escrita en portugués, destinada al espectador carioca y para ella Puig, además, tradujo con minucia los tangos interpretados por el cantor rioplatense. Ese año también se publicó Cae la noche tropical, su segunda novela escrita en tierra brasileña, donde repetir y traducir son nuevamente los actos mínimos, fundamentales y siempre intricados que permiten a sus personajes encontrar, en la espiral del recuerdo y la conversación, una vida posible. El hecho de que en ella la traducción opere como una matriz que en la trama habilita el diálogo no hace sino ratificar la centralidad de Sangre de amor correspondido en la obra del escritor. En esta, desplegó la pregunta por la alteridad de la propia lengua en la exhibición de la traducción como parte del proceso mismo de escritura, interrogante que, al expandirlo más allá de la relación entre los idiomas, permite recorrer toda su literatura. 


\section{BIBLIOGRAFÍA}

Amícola, José. "Manuel Puig y la narración infinita". Historia crítica de la literatura argentina. Tomo 11. Elsa Drucaroff (coord.), Buenos Aires, Emecé, 2000, pp. 295-319.

Benjamin, Walter. La tarea del traductor. Trad. Fernando García Mendivil. Madrid, Ediciones sequitur, 2017.

Berman, Antorne. "La traducción como experiencia de lo/del extranjero. La traduction comme épreuve de l'étranger". Colección Hermes, Traductología: teoría y práctica. Cuadernos pedagógicos 2, 2005, pp. 2-27.

La traducción y la letra o el albergue de lo lejano. Buenos Aires, Editorial Dedalus Editores, 2014.

Blanchot, Maurice. La risa de los dioses. Madrid, Taurus, 1971.

CABrera, Delfina. Las lenguas vivas: zonas de exilio y traducción en Manuel Puig.

Buenos Aires, Prometeo Libros, 2016.

Derrida, Jacques. Psyché. Invenciones del otro. Buenos Aires, Ediciones La Cebra, 2017.

"La diferencia [différance]". Edición electrónica de www.philosophia.cl / Escuela de Filosofía Universidad ARCIS, disponible en: https://www.philosophia.cl/biblioteca/ Derrida/La\%20Diferencia.pdf

Dos Santos Menezes, Andreia. Sangue de amor correspondido $x$ Sangre de amor correspondido. Análise de um caso emblemático de contato entre o PB e o $E$. Tesis doctoral. Universidad de San Pablo, 2006.

Giordano, Alberto. Manuel Puig. La conversación infinita. Rosario, Beatriz Viterbo, 2001.

GoldChluK, GRACIELA. El diálogo interrumpido. Marcas de exilio en los manuscritos mexicanos de Manuel Puig, 1974-1978. Santa Fe, UNL, 2011.

Puig, Manuel. Sangre de amor correspondido. Barcelona, Seix Barral, 1998 [1982].

Sangue de amor correspondido. Río de Janeiro, Nova Fronteira, 1982.

Querida familia. Tomo 2. Cartas americanas. New York-Rio (1963-1983). Buenos Aires, Entropía, 2006.

“Manuel Puig”. Entrevistado por Saúl Sosnowski. Hispamérica 1, N³, 1973, pp. 69-80.

“Archivo Digital Manuel Puig". ARCAS, marzo de 2020, consultado el 21 de noviembre de 2021, disponible en: http://arcas.fahce.unlp.edu.ar/greenstone3/colecciones/collection/ puig/browse/CL1

Kozak, Claudia. "Manuel Puig, la política, el umbral”. Ciencia, Docencia y Tecnología 22, $\mathrm{N}^{\circ} 43,2011$, pp. 129-153.

Logie, Ilse y Julia Romero. "Extranjeridad: lengua y traducción en la obra de Manuel Puig". Revista Iberoamericana 74, N²22, 2008, pp. 33-51.

Maia González, Neide. "Pero ¿qué gramática es ésta? Los sujetos pronominales y los clíticos en la interlengua de brasileños adultos aprendices de Español/LE”. RILCE 14, N², 1998, pp. 243-263.

Romero, Julia (ed.). Puig por Puig. Imágenes de un escritor. Madrid, Iberoamericana, 2006. 
Venuti, Lawrence. "Strategies of Translation". Routledge Encyclopedia of Translation Studies.

Mona Baker (ed.), Londres y Nueva York, Routledge, 2001, pp. 240-244.

The Translator's Invisibility: A History of Translation. Londres, Routledge, 2008. 